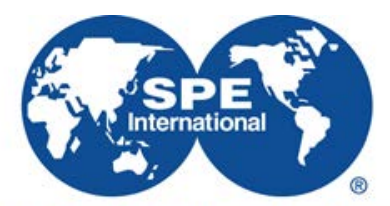

Society of Petroleum Engineers

\title{
SPE-198390-MS
}

\section{The Results of the Pilot Works on Well Completion Technologies and Continuous Monitoring on the Example of Extremely Long Horizontal Wells of the Yu. Korchagin Field in the Caspian Sea}

\author{
Segey Shtun, Alexander Senkov, and Oleg Abramenko, LUKOIL-Nizhnevolzhskneft LLC; Marat Nukhaev, \\ Siberian Federal University, Resman; Ilkam Mukhametshin, RusGazBureniye LLC; Konstantin Naydenskiy, Artem \\ Galimzyanov, and Ekaterina Popova, Resman \\ Copyright 2019, Society of Petroleum Engineers \\ This paper was prepared for presentation at the SPE Annual Caspian Technical Conference held in Baku, Azerbaijan, 16 - 18 October 2019. \\ This paper was selected for presentation by an SPE program committee following review of information contained in an abstract submitted by the author(s). Contents \\ of the paper have not been reviewed by the Society of Petroleum Engineers and are subject to correction by the author(s). The material does not necessarily reflect \\ any position of the Society of Petroleum Engineers, its officers, or members. Electronic reproduction, distribution, or storage of any part of this paper without the written \\ consent of the Society of Petroleum Engineers is prohibited. Permission to reproduce in print is restricted to an abstract of not more than 300 words; illustrations may \\ not be copied. The abstract must contain conspicuous acknowledgment of SPE copyright.
}

\section{Abstract}

This paper presents the experience of LUKOIL-Nizhnevolzhskneft of implementation of various completion designs and continuous monitoring systems for extended-reach horizontal wells. The article describes the evolution from stand alone sand control screens and passive inflow control devices to the introduction of multi-zone advanced smart wells with inductive coupling. In addition, the work presents experience with fiber-optic distributed temperature measuring systems and chemical tracers.

Since 2010, There are a lot of advanced technologies for well completion and continuous monitoring has been introduced at the field named after Yu. Korchagin, including nozzle-based inflow control device (ICD), autonomous ICD, ICD with check valve, sliding couplings, multiposition couplings, interconnected sand screens, fiber optic systems, chemical tracers, hydraulic and electric smart wells. The application of some technologies turned out to be limited in the conditions of the field named after Yu. Korchagin, part of the technologies had limited implementation due to the long length of horizontal wells, and some technologies showed unique benefits and were recommended for further wide implementation.

Pilot projects of some technologies, as well as the use of various completion systems and continuous monitoring systems at the wells of the Yu. Korchagin field, allowed LUKOIL-Nizhnevolzhskneft not only to solve current operation problems, but also to select optimum technologies for usage in the following fields of Caspian shelf.

\section{The need for pilot projects in the field named after Yu. Korchagin}

A significant amount of pilot projects on well completion technologies and continuous monitoring is associated with the need to confirm the feasibility of various technologies in the Caspian shelf and select the optimal technologies for implementation on the following LUKOIL-Nizhnevolzhskneft projects, including the fields named after Yu. Korchagin, named after V. Filanovsky, Rakushechnoe, Khvalynskoe, Sarmatskoe, "170 km" and others (Figure 1). 


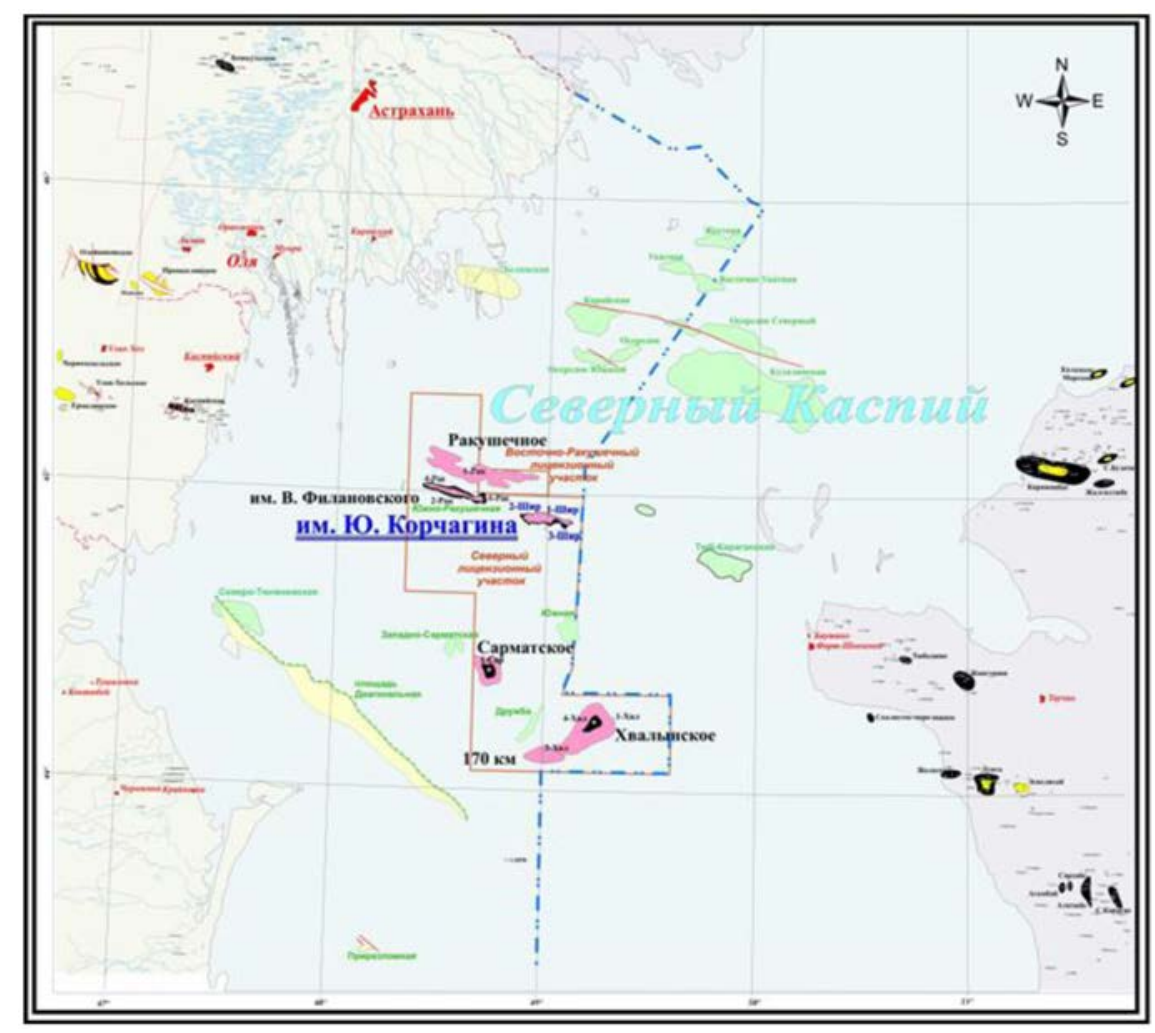

Figure 1-LUKOIL-Nizhnevolzhskneft oil fields on the Caspian shelf

The Y. Korchagin field is the first of the fields commissioned by LUKOIL-Nizhnevolzhskneft in the northern part of the Caspian Sea. The Neocom-Volga reservoir, that is the main object of development, is represented by a thin oil rim lined with active aquifer throughout the entire area of the reservoir with a massive gas cap. The oil and gas condensate reserves of terrigenous sediments of the Neocomian formation is the main object of development and provides the main production at the Yu. Korchagin field. The object is an oil rim of low power $(\sim 20 \mathrm{~m})$ with a massive gas cap $(\sim 100 \mathrm{~m})$ and underlying aquifer (Figure 2$)$. The position of the gas-oil contact of the formation of the Neocomian layer has a mark $(-1517 \mathrm{~m})$, and the oilwater contact $(-1537 \mathrm{~m})$. The net pay zone of the oil rim has significant gas and water-oil transition zones and is characterized by heterogeneity in filtration properties (Svarovskaya, 2014).

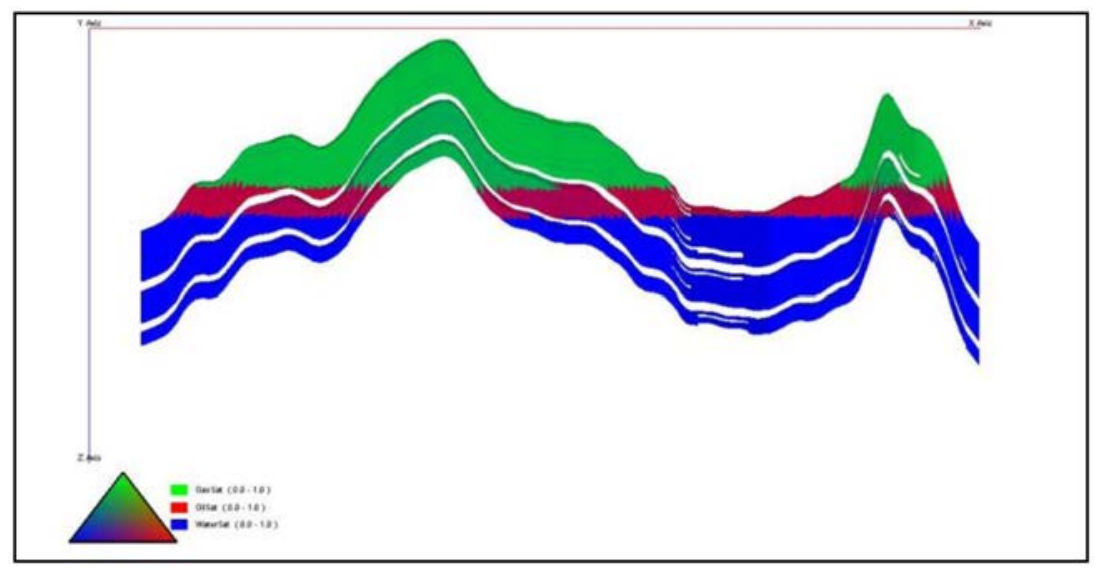

Figure 2-Section of the Y. Korchagin field 
In 2010, the field was put into production. Now, 24 production wells, 4 water injection wells and 2 gas injection wells have been drilled at the field named after Yu. Korchagin.

Distinctive features of the development of the Neocomian deposits of the field named after Yu. Korchagin is that the drilling of target formation with different characteristics of the reservoir is carried out by horizontal wellbore of extended length (up to 5000 meters). Accordingly, pressure losses along the wellbore, as well as various reservoir porosity and permeability along the length of the horizontal section, lead to an uneven distribution of pressure drawdown and gas breakthrough in the toe part of the horizontal wellbore.

Difficult geological conditions, and the results of the initial period of operation, determined the need for changes in the design of the elements of the lower well completion. In order to solve the problem of controling gas breakthrough, eight types of reservoir completion were implemented in the oil field, from simple systems - slotted liners to advanced smart well completion with remotely operated valves. The evolution of lower completion technologies at the field named after Yu. Korchagin is shown in Figure 3.

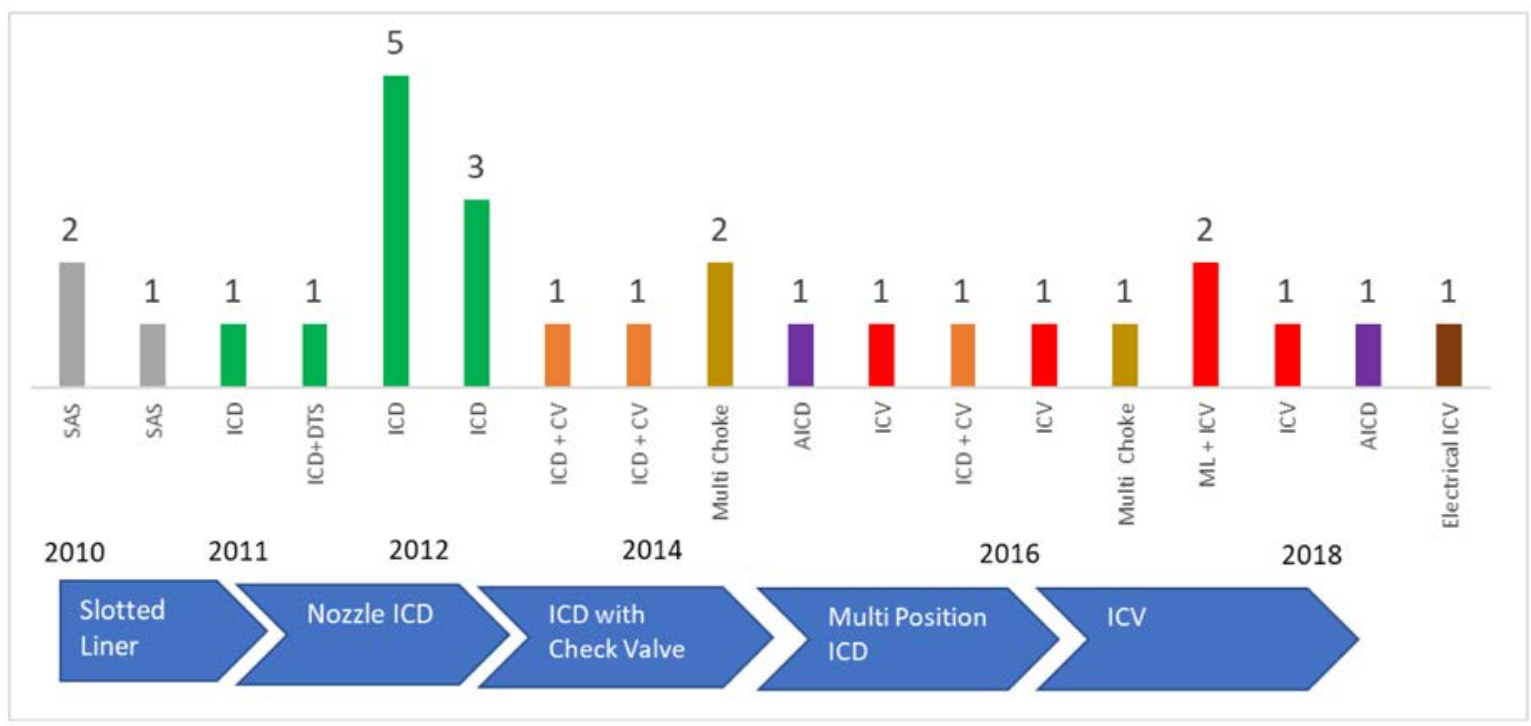

Figure 3-The evolution of lower completion technologies at the field named after Yu. Korchagin.

\section{The evolution of lower completion systems}

The slotted liner is one of the simplest types of completion. This type of well completion was used in the first three wells (2010-2011) in the carbonate reservoir of the Volga layer, which is characterized by minimal sand production. Figure 4 shows the completion scheme of the horizontal well of the Volga layer. Well completion is represented by $178 \mathrm{~mm}$ slotted liners and open hole swellable packers. 


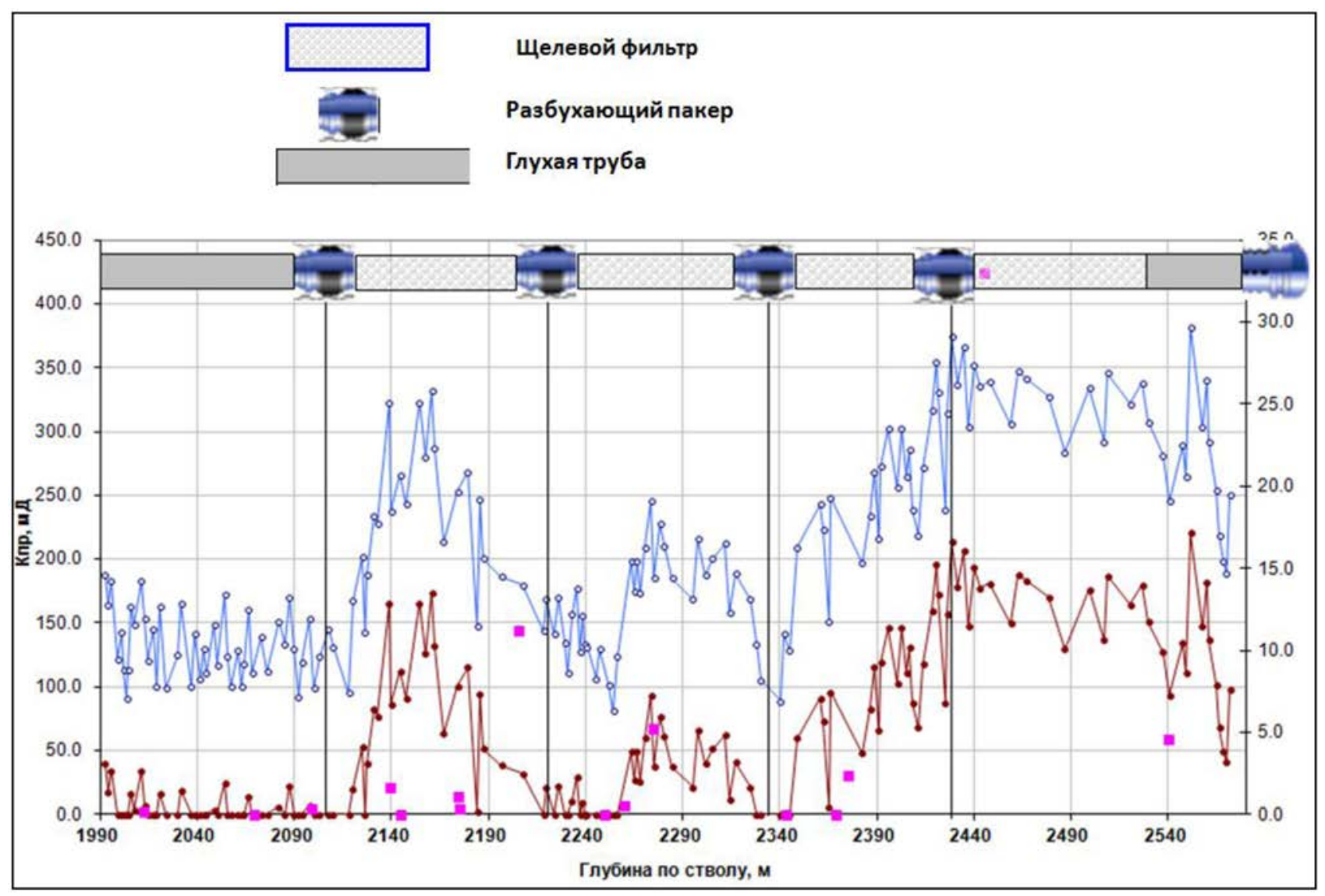

Figure 4-The Volga layer wells completion

Completion with a slotted liner showed low efficiency in the presence of an extensive gas cap due to the impossibility, because of design features, of restricting gas breakthroughs in the wellbore. The production of the wells was characterized by sharp increase in GOR, which required limiting the flow rates of the wells for the possibility of their uninterrupted operation. Installation of casing swellable packers allowed not only to prevent overflow through the annulus, but also to carry out repair and isolation work to re-complete the well by installing a blank pipe opposite the gas breakthrough interval.

Slotted liners as a completion were used only in the initial period of field development under conditions of high uncertainties of the geological structure and geological and physical properties of the reservoir.

\section{Passive inflow control devices}

At the first production wells of the Neocomian formation of the Yu. Korchagin field, nozzle type of for passive inflow control devices with sand screen have been used. These devices create additional pressure drops by restricting the flow area (Figure 5). The ICDs are installed at the stage of well construction and cannot be replaced during well life Thus, in different sections of the well, it is possible to create different resistance to flow from the formation into the well (different sizes of nozzles). This allows to equalize the pressure drawdown profile along the wellbore and reduce the effect of the "heel-toe" of the well. Figure 6 shows the well completion design using nozzle type ICDs. The heel of the well is equipped with nozzles of small diameter $2 \times 1.6 \mathrm{~mm}$, and the nozzles of $4 \times 4.0 \mathrm{~mm}$ are installed in the toe of the well. 


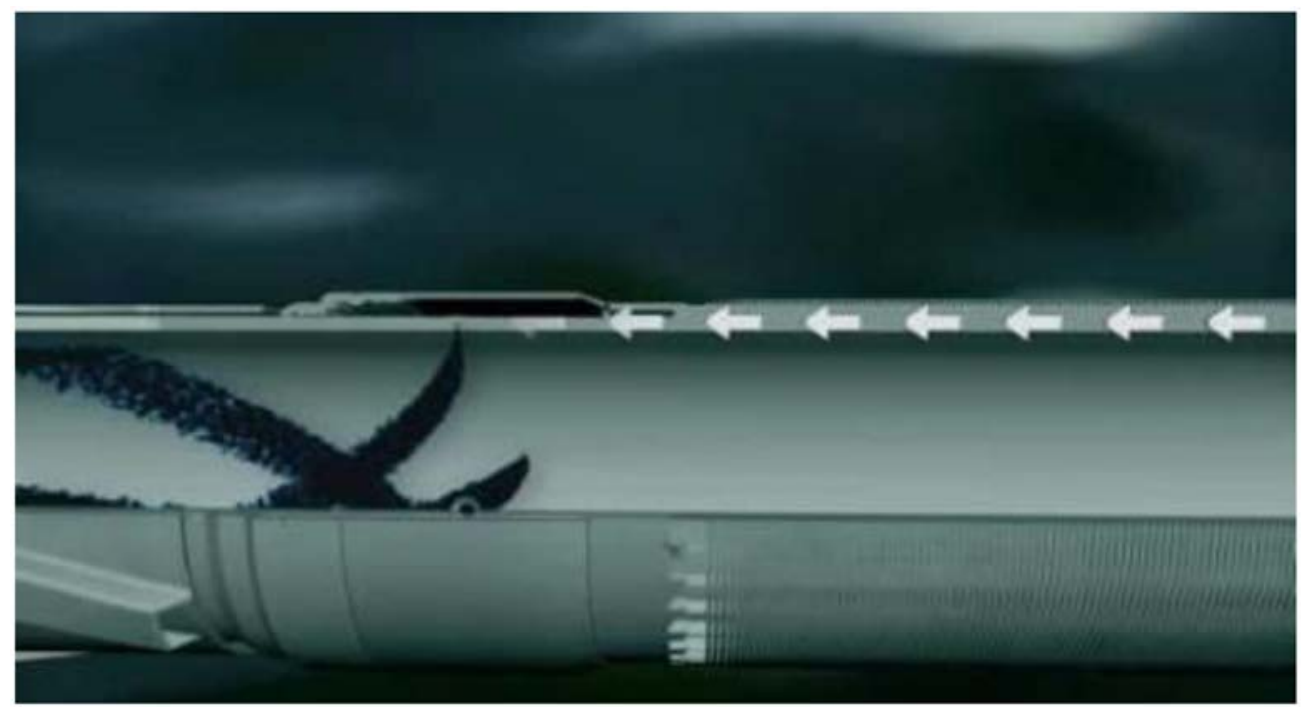

Figure 5-Nozzle based inflow control devices.
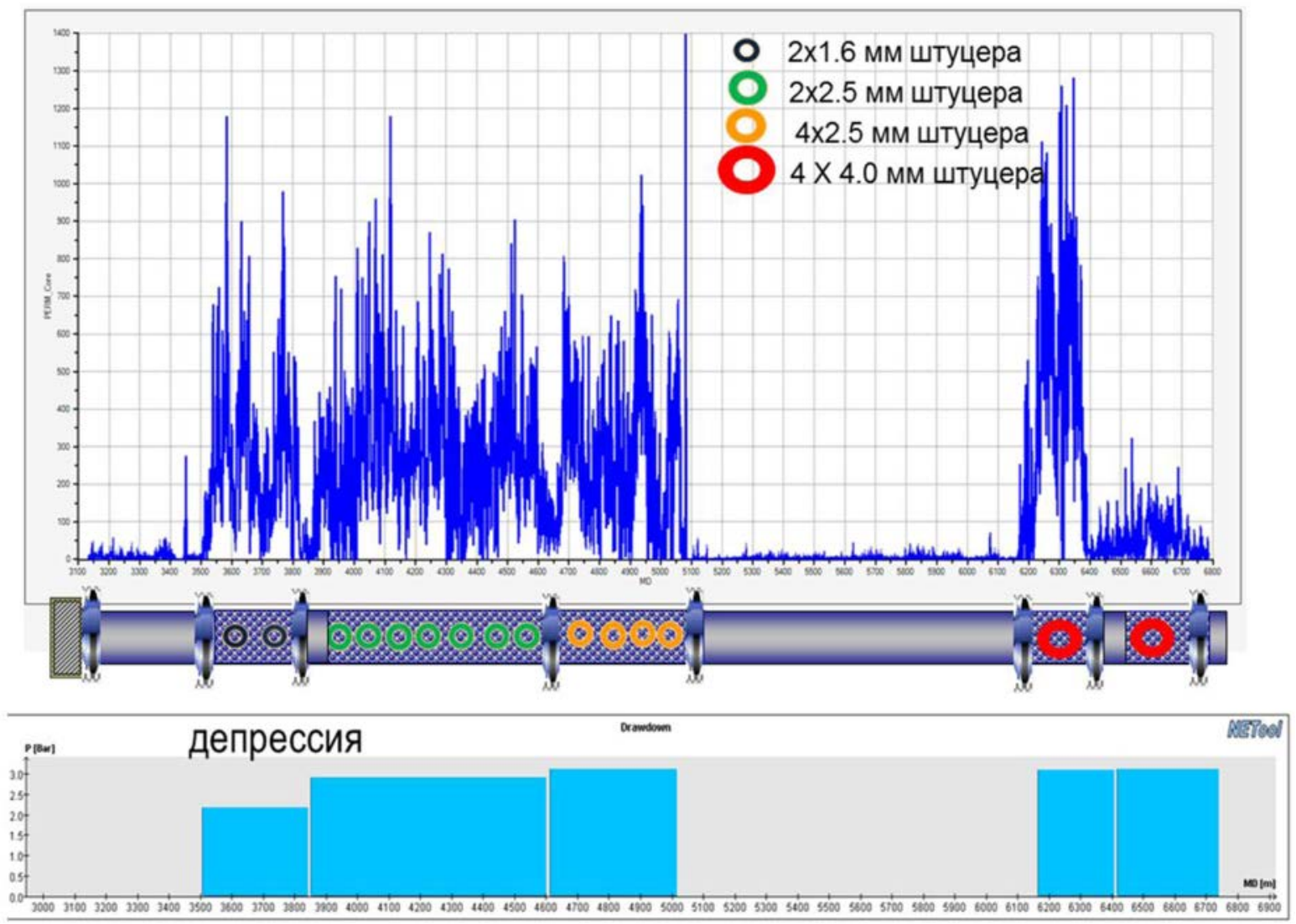

Figure 6-Design of the well with a nozzle-based ICD

Experience in operating such systems in the field named after Yu. Korchagin shows that passive inflow control devices allow to equalize the inflow profile and postpone the start of water breakthrough, but, unfortunately, these ICDs do not effectively mitigate gas breakthroughs due to its high mobility and velosity.

Passive ICDs with a check valve were first used in the world at the field named after Yu. Korchagin (Figure 7). One of the main goals of using this technology was the possibility of running to the hole the liner with circulation without a washpipe. When the liner is reaching target depth, a check valve prevents completion fluid from passing through the screens and allows circulation through the liner shoe, thereby 
reducing the risk of getting stuck while running into the hole. When the well is put into operation, the check valve frees up the passage through the nozzle and does not impede production.

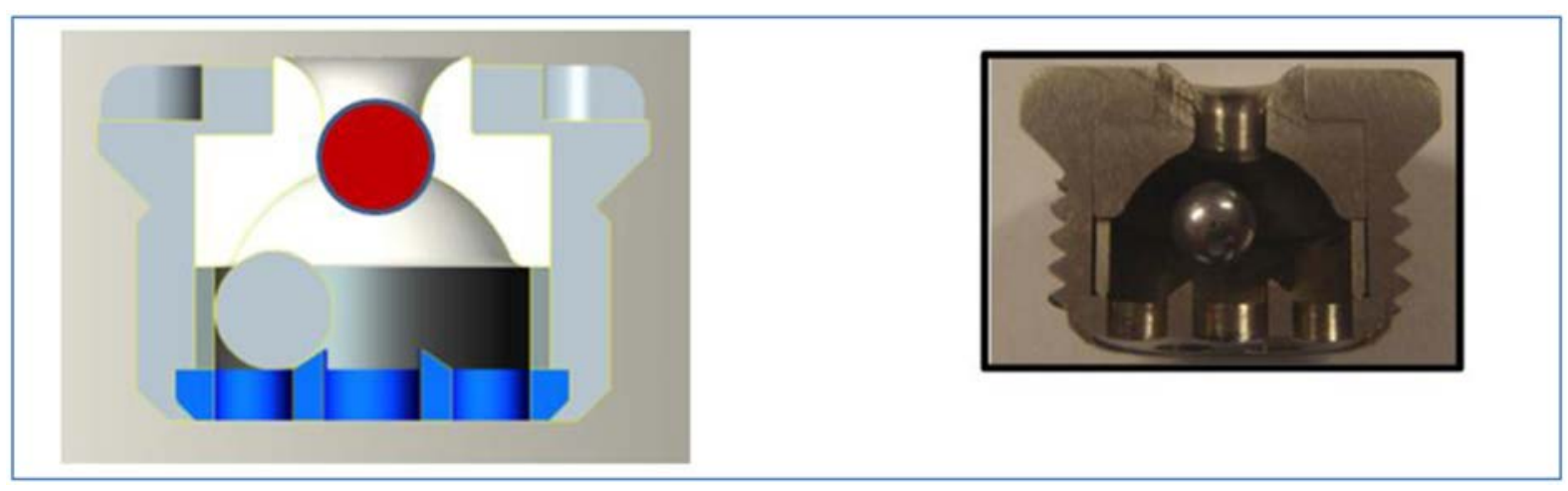

Figure 7-Nozzle ICD with a check valve

Due to unability of nozzle systems to limit gas breakthrough, it was decided to conduct pilot tests of autonomous inflow control devices. AICD is a system for limiting gas breakthroughs, which is based on a valve with a floating disk - an RCP valve (Figure 8). RCP valves have been used successfully in the development of the Troll offshore field in Norway. The valve's operating mechanism is based on Bernoulli's law, where the produced fluid passes through a nozzle with a floating disk, which changes the flow restriction based on the physical and chemical properties of the fluid. A less viscous fluid passes through the RCP valve with higher velocity and create low pressure drop above the disc, causing the disk to rise and thus obstruct the flow. The experience of using AICD valves in two wells of Yu. Korchagin field does not allow us to state definitely the effectiveness of using RCP valves for the conditions of this field (Semikin, 2017). Figure 9 shows the well operation parameters with autonomous inflow control devices.
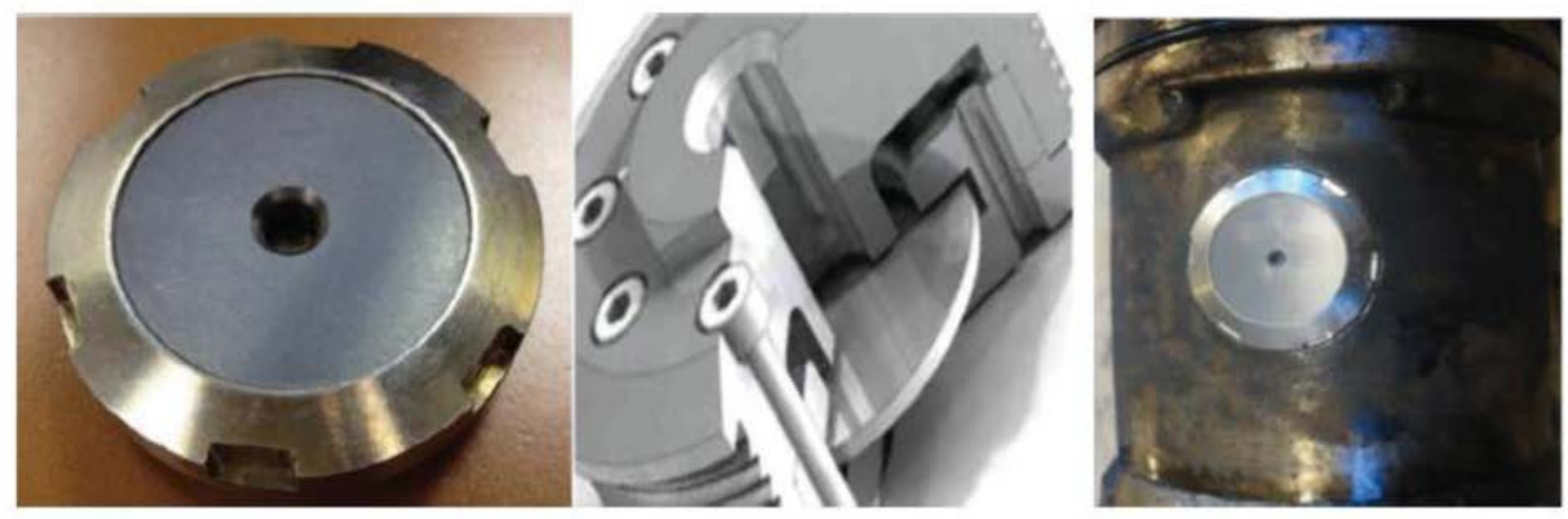

Figure 8-Autonomous inflow control device 


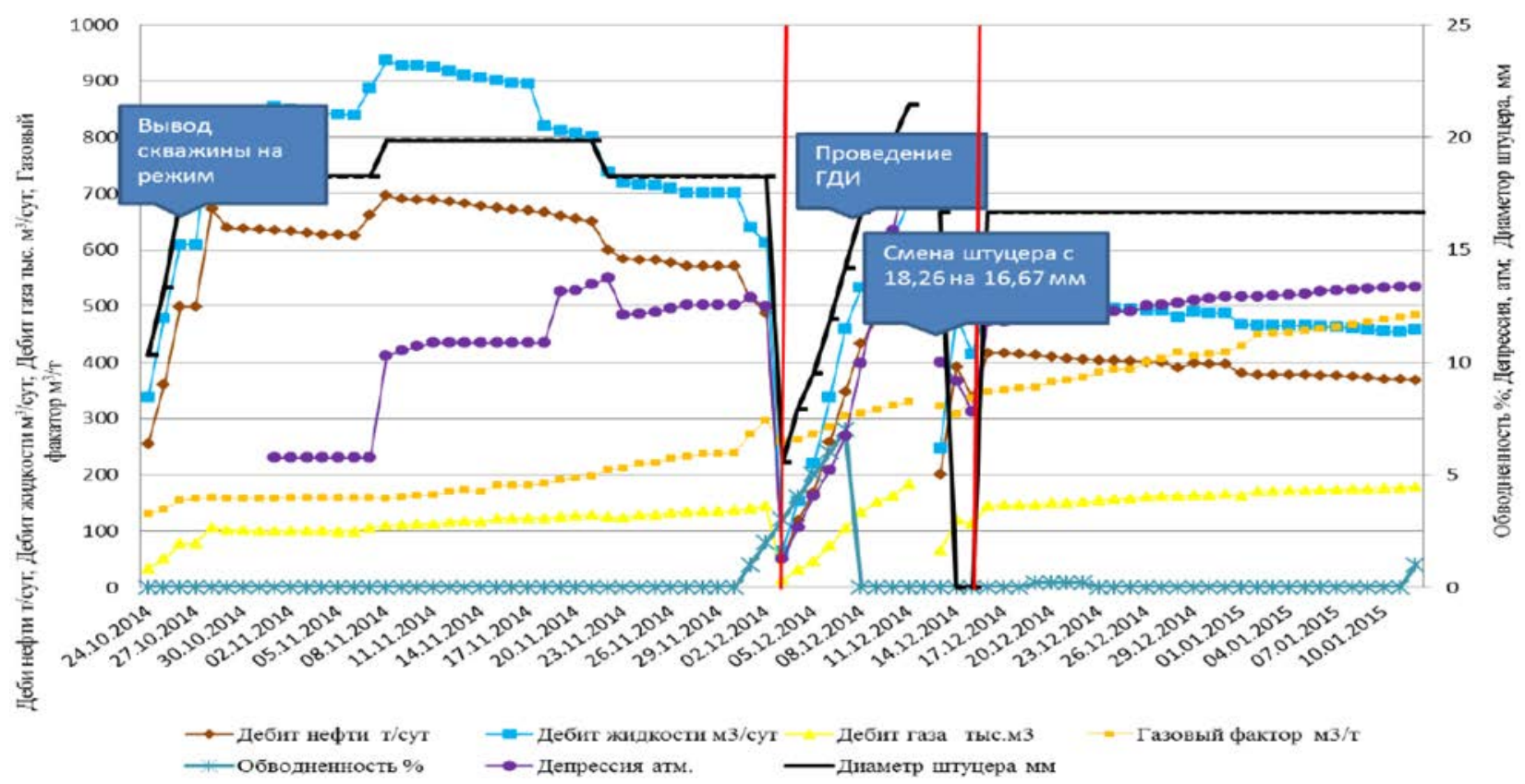

Figure 9-Well operation with autonomous inflow control devices

Isolation of gas breakthrough zones is possible when $2 \mathrm{x}$ or $3 \mathrm{x}$ position sliding sleeve are used as part of the horizontal well completion (Figure 10). This equipment is switched from one position to another using a hydraulic shifting tool, which is delivered to the well by tubing/coiled tubing, or by a well tractor.

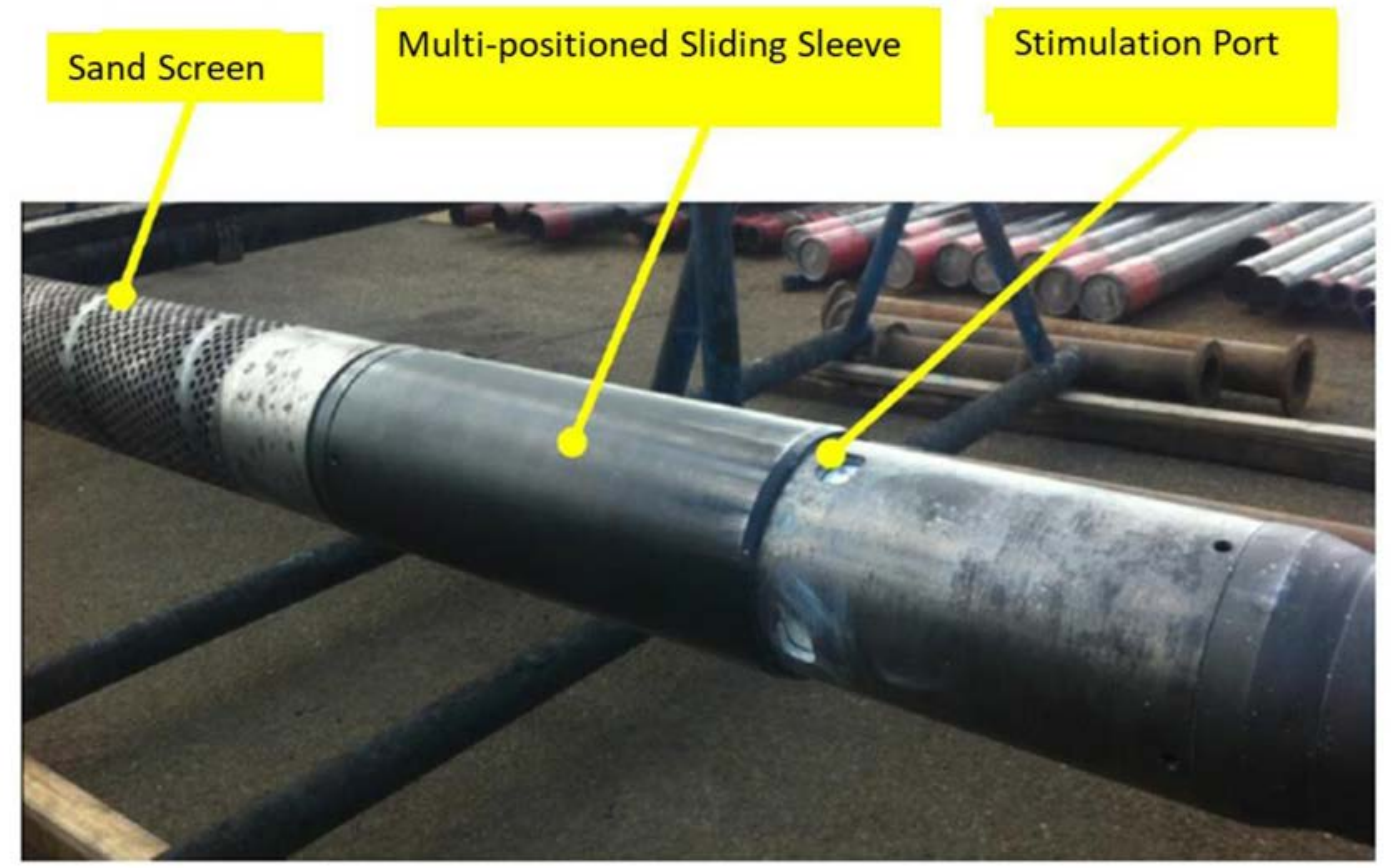

Figure 10-3-position sliding sleeve

The disadvantages of using positional sliding sleeves in an offshore field named after Yu. Korchagin include the following: the need to use a drilling rig for downhole operations; the difficulty of assessing the position, since the effort to move from one position to another requires an effort of less than one ton; the difficulty of delivering the hydraulic tool to the far zones, in the case of using sleeves in extended 
reach drilling wells, as well as the need for guaranteed closure of all sleeves in a certain zone to isolate gas breakthroughs in this zone.

As a solution to the above problem, it was proposed to use screen assemblies (clusters) with one or two sliding sleeves for each zone (Figure 11). The transition of the formation fluid from one screen to another is carried out using a special casing connecting the screens. For this completion concept, the switching position of the sleeves is carried out using the hydraulic tool delivered on the well tractor.

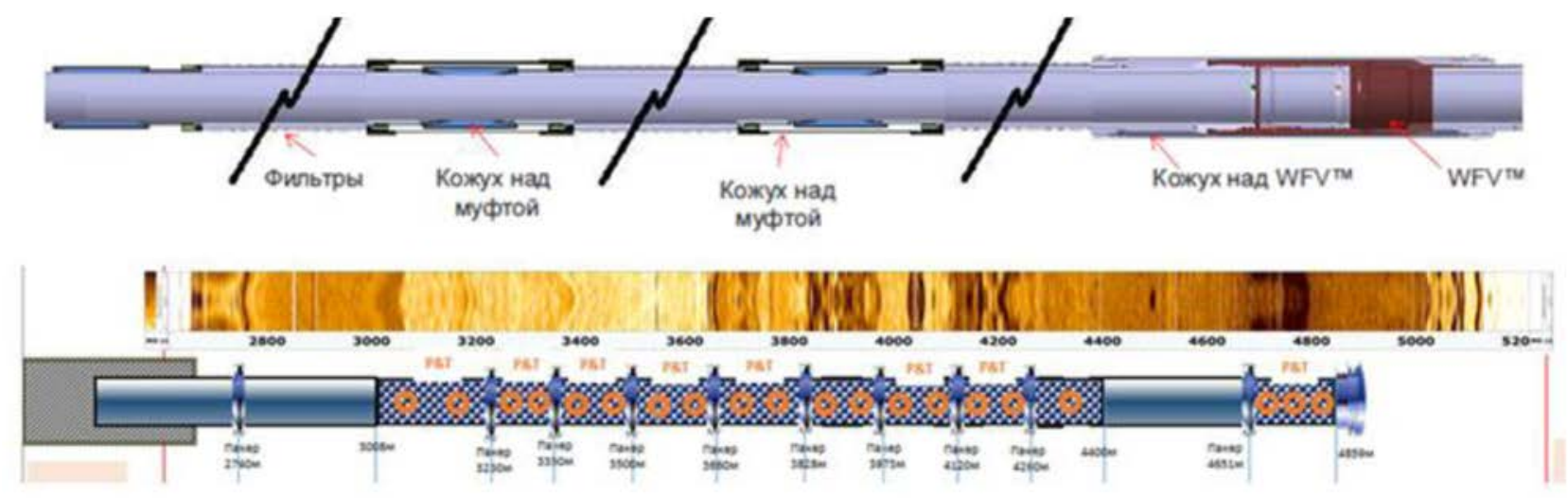

Figure 11-Combining screens into clusters (assemblies).

\section{Fiber optic monitoring systems}

In order to evaluate the operation of various completion systems (especially during the extended horizontal wells operation), make operational decisions on geological and technical measures, and make changes in the production, it is necessary to conduct production logging test (PLT) at various stages of well operation.

It is worth noting that the high content of free (breakthrough) gas in the product, the high production rate of the well and the significant length of the horizontal section of the well considerably complicate the work of cable technologies for PLT of the formation. The main technical problem in the testing of horizontal wells is the need to deliver instruments in the testing zone, which is carried out by a coiled tubing or a well tractor. The involvement of third-party contractors is required to solve this problem, which increases the cost of the PLT.

There is also a technical limitation when performing PLT at the stage of field development, due to the design features of the operational complex of the offshore ice-resistant platform. To deliver tools to the bottom of the well, it is necessary to use tractor systems that significantly increase the length of the downhole assembly, reaching about $25 \mathrm{~m}$. Installation of a wellhead lubricator of such a length is possible only if the drilling portal is displaced in the stern and the first two rows of slots are released on the spider deck. Even so, a deck crane must be used to secure the top lubricator roller. Given the duration of the test, this creates additional difficulties for loading and unloading operations between support vessels and the platform. In addition, the intensity of technological operations on the drilling complex and the pipe deck of the platform during well drilling eliminates the possibility of simultaneous work (drilling and production logging). All of the above points significantly reduce the frequency of PLT of the wells of the Yu. Korchagin field and, therefore, it is difficult to talk about the full monitoring of the operation of the wells.

Thus, it was decided to carry out pilot works on monitoring horizontal wells using fiber-optic temperature measurement systems (Chertenkov, 2012). This approach is one of the possible solutions to ensure continuous monitoring of the inflow profile in the wellbore and is a method that does not require intervention in the well during its operation.

In a horizontal well with a low drawdown, the installation of fiber optic cable was carried out on the outer surface of the casing of sand screen. This method of installing fiber optic cable in combination with inflow control devices provides a unique opportunity to measure directly inflow temperature in individual 
zones of the wellbore, based on the Joule-Thomson effect. In addition, the effect of caloric mixing in the wellbore is excluded. This phenomenon occurs when mixing fluid from different production zones inside the wellbore and it is a complicating factor in the interpretation. With this arrangement of the cable, the change in the temperature of the inflow will be associated exclusively with the difference in bottomhole pressure in a particular section of the wellbore and with the properties of the fluid. Monitoring changes in these parameters over time provides a unique opportunity to locate the flow of free (breakthrough) gas into the wellbore. Figure 12 shows a diagram of the lower completion of one of the wells where a distributed temperature measurement system was installed. This figure shows the arrangement of casing packers and inflow control devices depending on the permeability profile along the wellbore.

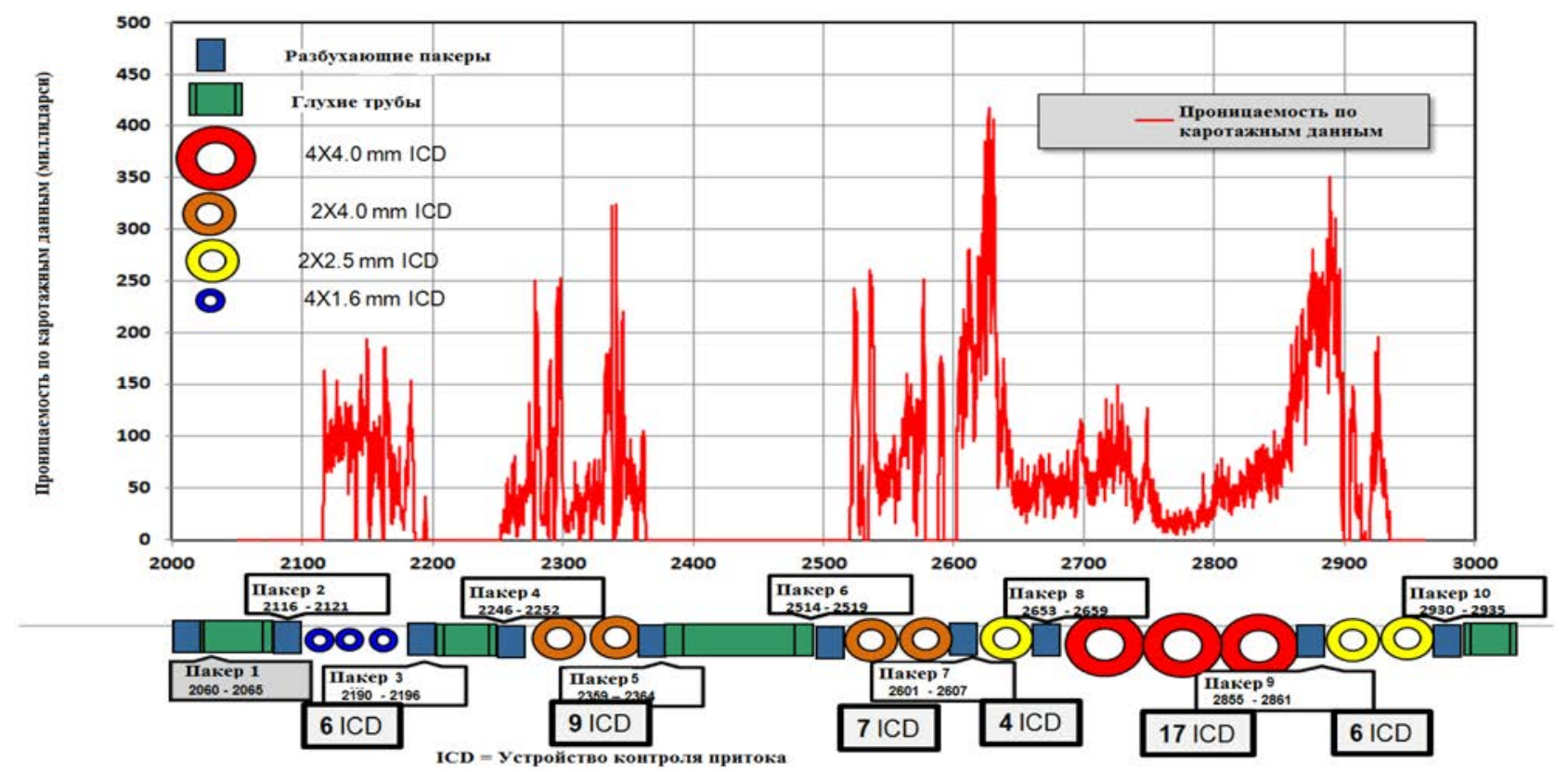

Figure 12-Well completion diagram with inflow control devices

Connection of the upper (tubing string) and lower (liner) completion was performed using the "wet connection" system, which consists of two parts: a stinger and a receiver. Such a system allows in a wellbore conditions to make a mechanical connection of a fiber optic cable. Each section of the liner has a specially provided longitudinal slot for laying control lines, which houses the fiber optic cable of the distributed temperature measuring system in a flat braid (Figure 13). 


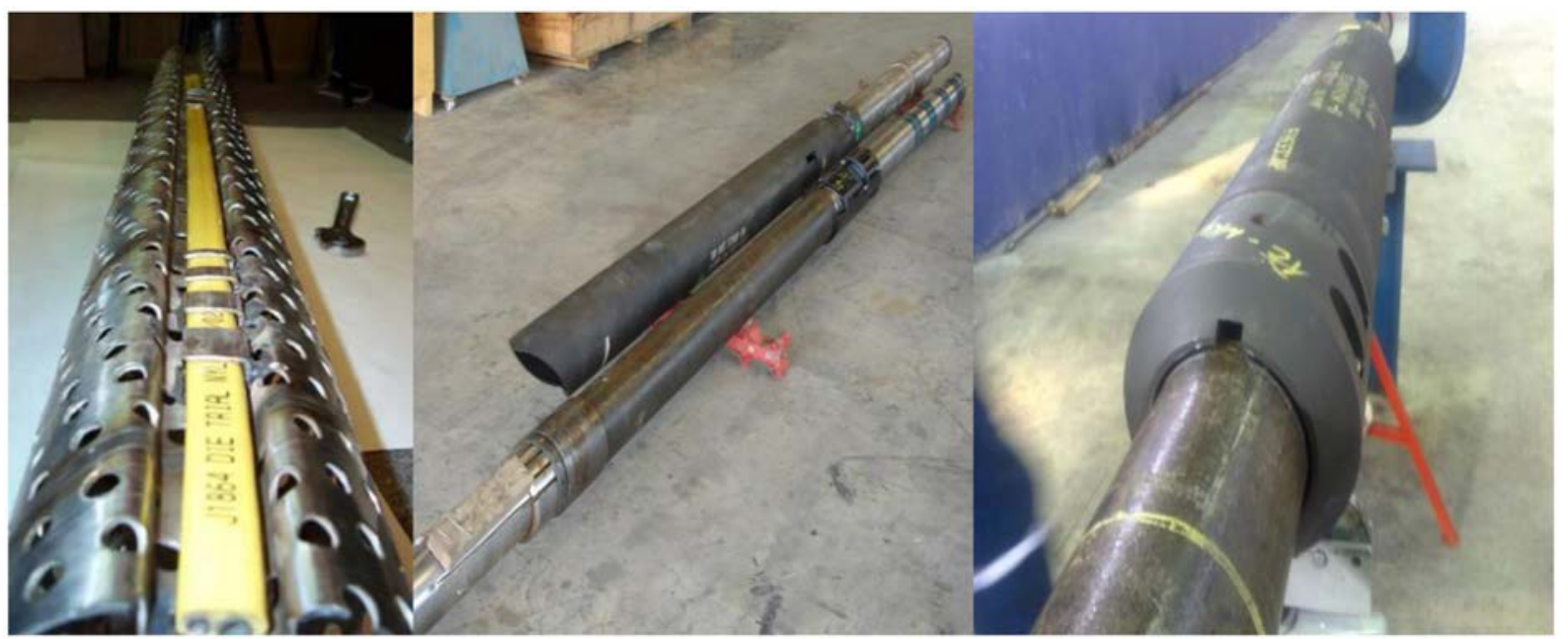

Figure 13-Sand screen with fiber optic cable in a flat braid; system stinger and receiver; swellable packers with wired channels

For fiber-optic distributed temperature measurement, an industrial laser is used that sends light pulses through the fiber at a speed of 10 nanoseconds. With the passage of each beam of light, a small amount of it is reflected by the molecules of the fiber. Such backscattered light is analyzed to measure temperature over the entire length of the optical fiber. Figure 14 shows a three-dimensional image that includes all the data of the distributed temperature measurement recorded in the well during 6 months of observation.

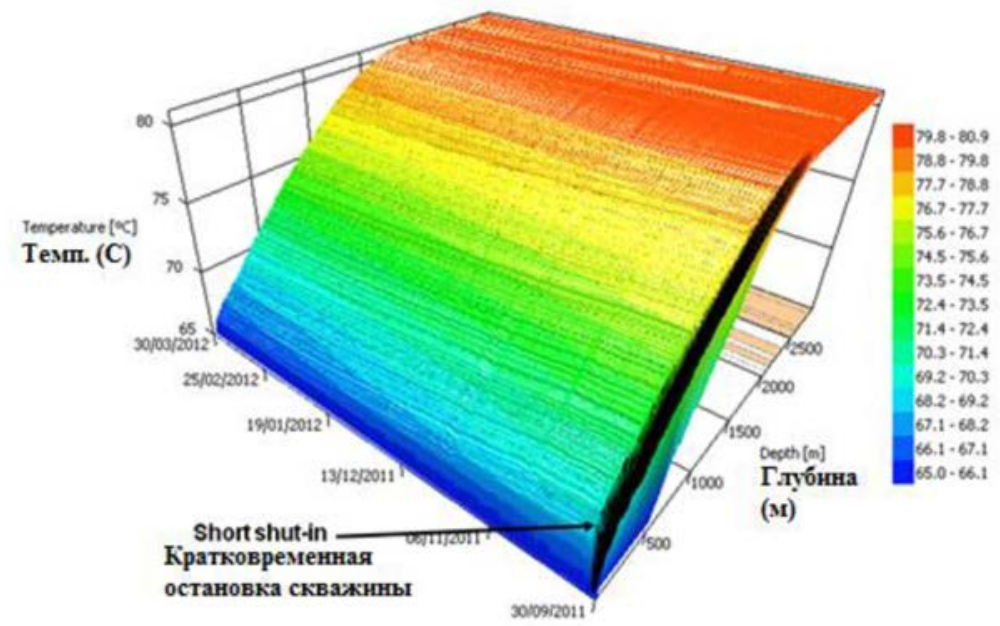

Figure 14-Distributed temperature measurement data for the entire wellbore

Figure 15 shows the selected temperature curves obtained by the distributed temperature measurement system for the specified time (one curve for each month) combined with the gamma-ray log. The blue line indicates the trajectory of the well and its position in depth. Note that with an increase in the gas content of the produced fluid, a decrease in temperature is observed due to a change in the thermal properties of the well fluid. There is a general tendency to a decrease in temperature over time, and in some zones of the reservoir there is an increasing effect of cooling the fluid to $0.6^{\circ} \mathrm{C}$ over the specified period of time. Figure 16 shows a 3D model of visualization based on all the data of a distributed temperature measurement for the indicated measurement recording period, where the increasing effect of fluid cooling at individual zones of the reservoir over time is clearly traced. The temperature of the inflow, taking into account the Joule-Thomson effect, measured in the annulus at various productive zones of the reservoir, depends on the magnitude of the drawdown and the Joule-Thomson thermodynamic coefficient, which is a quantitative 
characteristic of the Joule-Thomson effect and is determined by the ratio of the change in gas temperature to the causing it pressure change. Therefore, if the magnitude of the depression on the formation remains stable, the magnitude of the temperature change will reflect the change in the Joule-Thomson coefficient for the well fluid flow. Therefore, the temperature measured in the production zone of the reservoir using a fiber optic cable located on the outer wall of the filter is not the temperature of the mixed fluid flow from different intervals of the well, but, on the contrary, is a direct indicator of the properties of the fluid flow directly when it enters from the formation into the well, subject to the conditions of a stable value of reservoir pressure. Unfortunately, oil and water have almost the same Joule-Thomson coefficients, so it was impossible to use temperature measurements to determine the intervals of water supply from the moment the well was put into operation, since the well was commissioned with a rather high $(>40 \%)$ percentage of water in products. However, with regard to the increase in the value of the field gas factor over time, a direct indicator of this increase will be a decrease in the temperature of the reservoir fluid in the local zones of the horizontal wellbore. This is because the Joule-Thomson coefficient for gas is significantly different from the thermodynamic coefficients of oil and water. The data shown in Figures 15 and 16 reflect the presented dependence and allow us to determine the zones of the reservoir in which breakthroughs of free gas of the gas cap occur (Semikin, 2017).

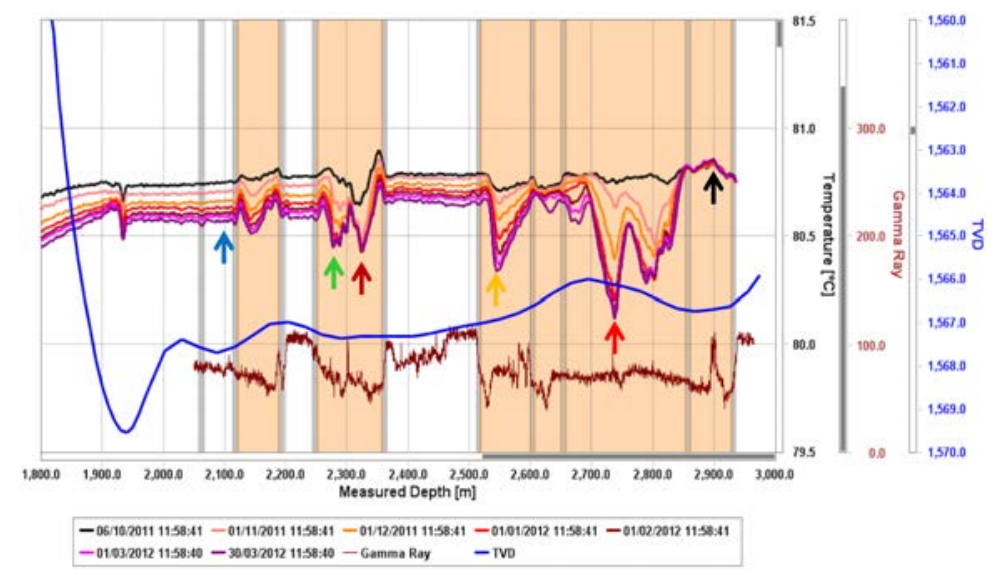

Figure 15-Temperature curves taken during the measurement period

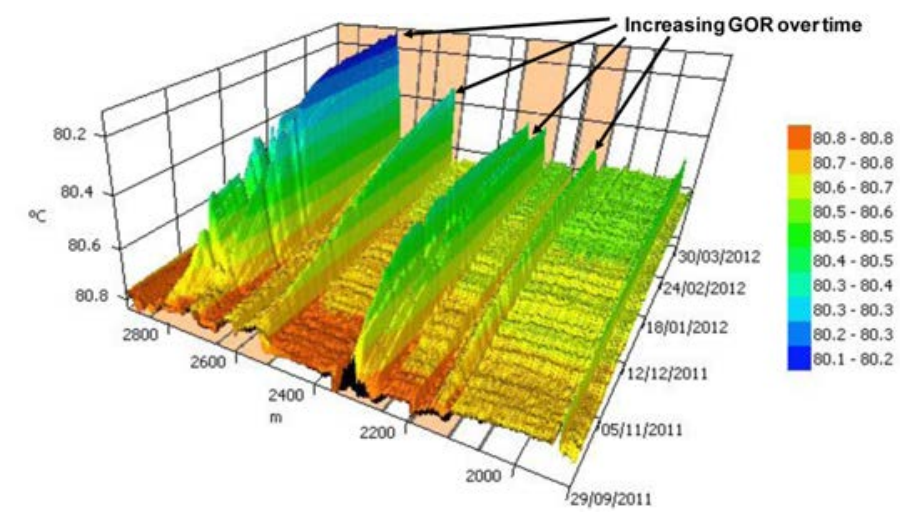

Figure 16-Three-dimensional image of measurements obtained by a fiber-optic temperature measurement system in time dependence

\section{Chemical tracers}

Chemical tracers are polymer matrices that are installed on lower completion (sand screens, inflow control devices, multistage hydraulic fracturing equipment and others). These matrices contain intelligent tracers embedded in them that begin to release from the polymers when they contact with the target formation fluid 
(water or oil). The technology of intelligent chemical tracers has been developed to work with the target formation fluid (oil or water) for a quite long period of time (up to 5-10 years). To analyze the operation of each well zone, many unique "intelligent" chemical tracers have been developed: 60 of them are designed for diffusion in oil and another 60 for diffusion in water. Thus, it is possible to monitor continuously the operation of a horizontal well with 60 zones.

The well study is as follows. After runnning the completion equipment with pre-installed tracers, the well is put to production and further operation. Upon contact with the target fluid (water or oil), the polymer matrices begin to release these tracers, which are carried out by the flow of formation fluid. Moreover, the rate of release of tracers is constant and does not depend on the flow rate of fluid. Samples are taken according to a specific sampling program. Samples taken are sent to the chemical laboratory, where they are analyzed for the content of tracers. Based on the results of the analysis of samples, a report is prepared on the operation of this horizontal well. At each stage of the well life the goals of the well survailance and the sampling program can be different.

For example, at the stage of well clean-up sampling is carried out with a minimum interval of 30 minutes and a gradual increase to 6-12 hours within 2-3 days. Analysis of these samples allows a qualitative assessment of the efficiency of wellbore cleaning and the operation of each well interval. If it is necessary to obtain a quantitative analysis of the inflow of each interval, it is necessary to shut the well for 6-18 hours. This shut is necessary so that in a static mode a cloud of high concentration of tracers is formed near the tracer matrices.

When resuming production (opening the well), the "clouds" of the tracers are flushed out by the inflow of fluid from the reservoir, as well as by the flow in the pipe and then transported to the wellhead, the sampling point. For this type of logging, sampling is carried out with an interval of 5 . . 60 minutes for 1-2 days. By measuring the time interval (or volume) required to flush indicator material from each section of the well and comparing the parameters of the reservoir model with actual production data, a quantitative estimate of the inflow for each interval can be obtained (Figure 17). In the case of increased water cut in the well, analysis of samples for the presence of "water" tracers will help to localize the zones of water breakthrough for subsequent water shut-off remedial job.

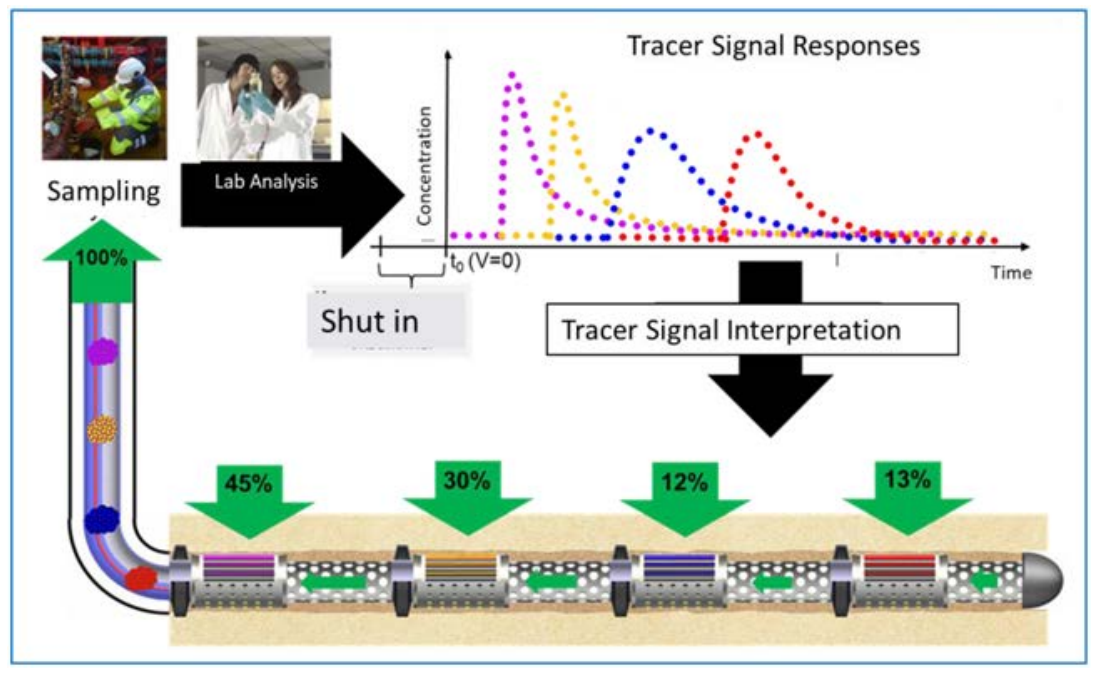

Figure 17-Production logging using intelligent tracers

The pilot well for the implementation of the chemical tracers was completed in October 2014. The length of the horizontal section of this well exceeded 4000 meters. The lower completion of the well is a composite liner of pipes with diameters of $168 \mathrm{~mm}$ and $139 \mathrm{~mm}$. Each pipe is a wire wrapped sand screen, in which an autonomous inflow control device is integrated. Polymer rods were installed in channels bounded by ribs 
located between the outer diameter of the pipe and the inner diameter of the screen element (Figure 18). After the logging data during drilling was interpreted, a group of engineers from the development department identified places for installing swellable annular packers (16 intervals separated by packers), as well as eight intervals for installing intelligent tracers in the lower completion for this pilot well (Shtun, 2016).

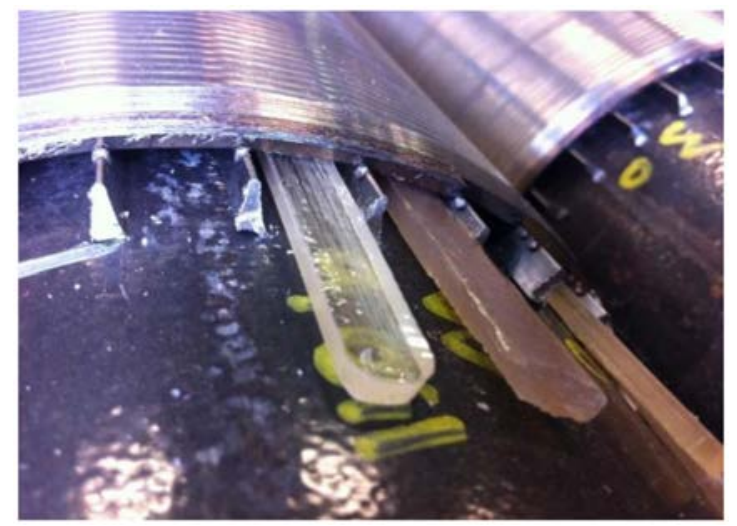

Figure 18-Installing intelligent tracers in the completion system

Intelligent tracer systems were named OS 1-8 for oil and WSC 1-8 for water to control the zone from the heel to the toe of the pilot well. This, in turn, means that the remaining eight intervals were left without a monitoring system, being "blind zones". In addition, "blind zones" alternating with controlled zones were also in the reservoir with similar permeability and porosity. The final layout of eight intelligent tracer systems along the horizontal part of the well is shown in Figure 19.

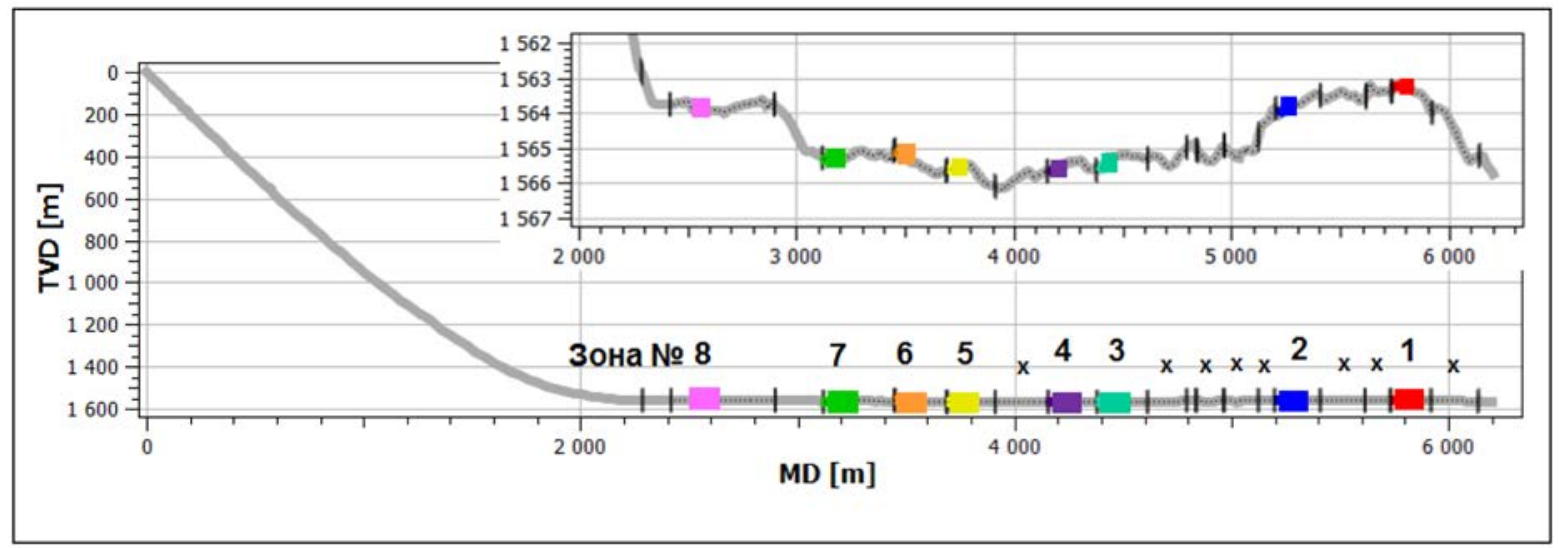

Figure 19-The arrangement of chemical tracers along the wellbore

During the logging of this pilot well, 8 major sampling campaign were performed for subsequent analysis (Figure 20), including the analysis of the quality of well development, quantitative assessment of the inflow and determination of the water breakthrough zones. 


\begin{tabular}{|c|c|c|c|}
\hline$\#$ & Date & Choke Size, $\mathbf{~ m m}$ & Type of survaillance \\
\hline 1 & Dec 2014 & 16.07 & Clean Up Efficiency. Quantitative Analysis \\
\hline 2 & Jan 2016 & 15.88 & Multi Rate Test \\
\hline 3 & $2015-2016$ & & Water Breakthrough interval allocation \\
\hline 4 & Aug 2016 & 11.92 & Quantitative Analysis \\
\hline 5 & Jan 2017 & 12.7 & Multi Rate Test \\
\hline 6 & June 2017 & 15.88 & Quantitative Analysis \\
\hline 7 & Feb 2018 & 16.67 & Quantitative Analysis \\
\hline 8 & 2018 & & Water Breakthrough interval allocation \\
\hline
\end{tabular}

Figure 20-Well monitoring using RESMAN inflow indicator technology

For each campaign, a quantitative distribution of the inflow over the intervals was obtained, including interpolation of the interval inflow into the blind zones. A significant conclusion was the confirmation that the entire open hole interval of a long horizontal is effective length of the well.

As an example, Figure 21 shows the results of a tracer monitoring campaing in January 2016 on various surface choke sizes, which allows identifying the following behaviors versus drawdown (Shtun, 2017):

- At a small choke size of $7.94 \mathrm{~mm}$, a general decrease in the productivity of zones (especially of the toe) is observed with a simultaneous sharp increase in the productivity of zone 7

- When switching to a $9.52 \mathrm{~mm}$ choke, zones in the toe (1 and 2) begin to work, the productivity of zone 7 decreases sharply

- Zone 7 is generally sensitive to changes in well operation

- Zone 5 is the least sensitive to nozzle changes

- Wnen chokes sizes are 11.91 .. 14.29, $16.67 \mathrm{~mm}$ zone 3 dominates

- The smallest deviation of the productivity of the zones from the expected in the stationary mode is observed on the choke $15.88 \mathrm{~mm}$.

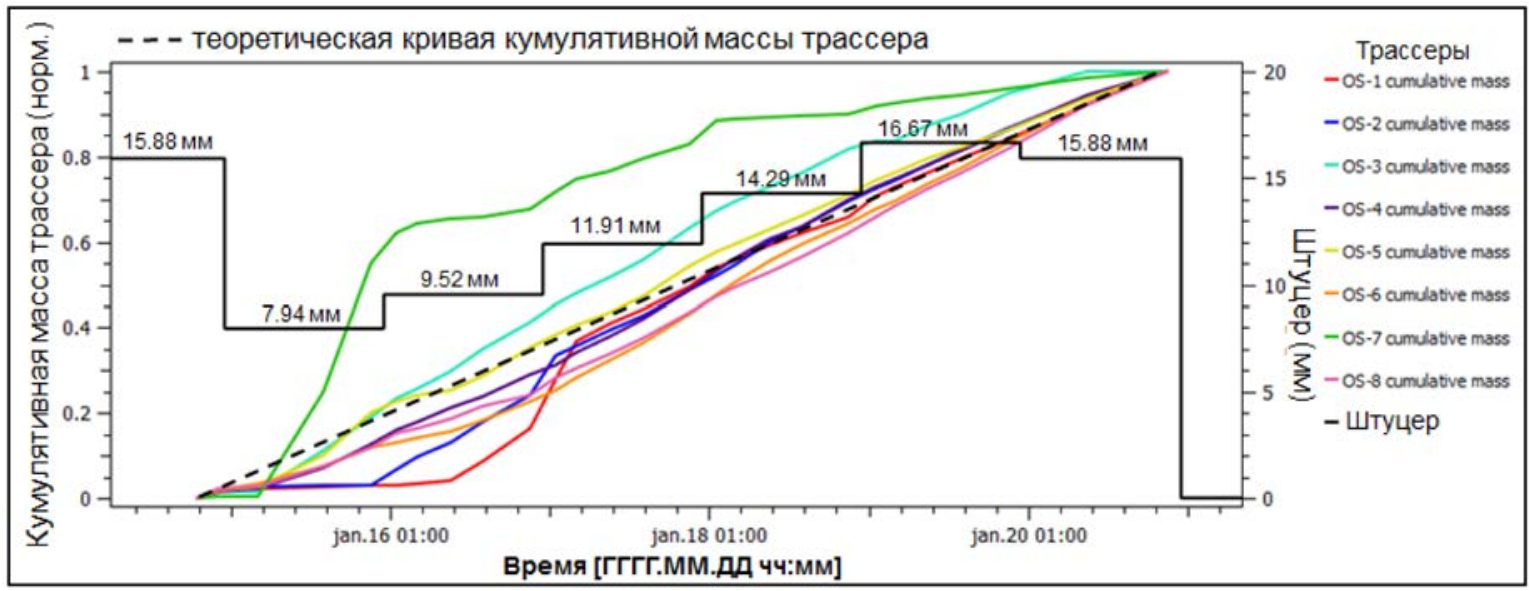

Figure 21-Qualitative assessment of the productivity of zones with various drawdowns

The introduction of the inflow chemical tracers at the field named after Yu. Korchagin allowed solving a wide range of problems of a traditional PLT without its implementation:

- Assessment of the efficiency of well development

- Monitoring changes in the productivity of intervals over time 
- Localization of water and gas breakthrough intervals

- Quantitative assessment of the distribution of inflows at intervals.

\section{Smart wells}

Part of the wells of the field named after Yu. Korchagin was equipped with smart wells with hydraulic valves. The basis of this completion system is the hydraulically adjustable downhole valves used to change the flow rate of fluids taken from the formation. This equipment allows, based on the data of downhole monitoring, to carry out the control of inflow from each zone quickly, which ensures uniform inflow along the entire length of the horizontal section. The management is carried out via hydraulic lines from the surface (Figure 22) in a wide range of nozzles (8 valve positions).

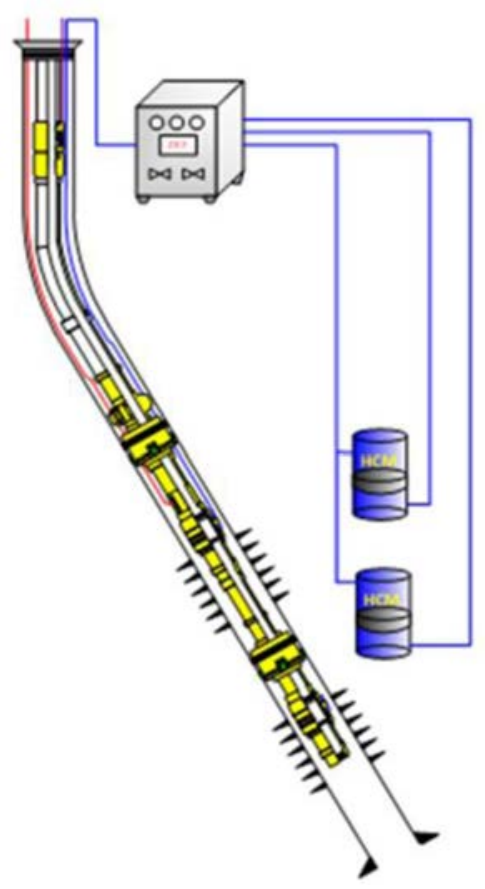

Figure 22-Management of smart wells using hydraulic lines

The inflow control valve (ICV) is an essential part of smart well completion technology and is used where selective control of production or injection is necessary. The ICV allows the operator to change the inflow for the interval without wellbore intervention jobs. Also, ICV adjustment allows to develop a well after drilling effectively to achieve the maximum potential production rate due to complete cleaning of the wellbore and ensures the distribution of drawdown along the horizontal wellbore for optimal reserves production.

In general, the use of smart wells made it possible to control the development and operation of each intervals and significantly increased the efficiency of these wells. When a gas breakthrough occurred, these intervals were turned off in real time without stopping the well and performing workover. A comparison was made of the operation of a well equipped with a smart well with hydraulic valves and neighboring wells operating with slotted liners. It was found that if for a standard well completion there was a premature gas breakthrough, a sharp increase in gas production and a decrease in oil production, then after installing an smart well on a new drilled well, gas breakthroughs were not observed and the well was operating in a more stable regime (Figure 23). 


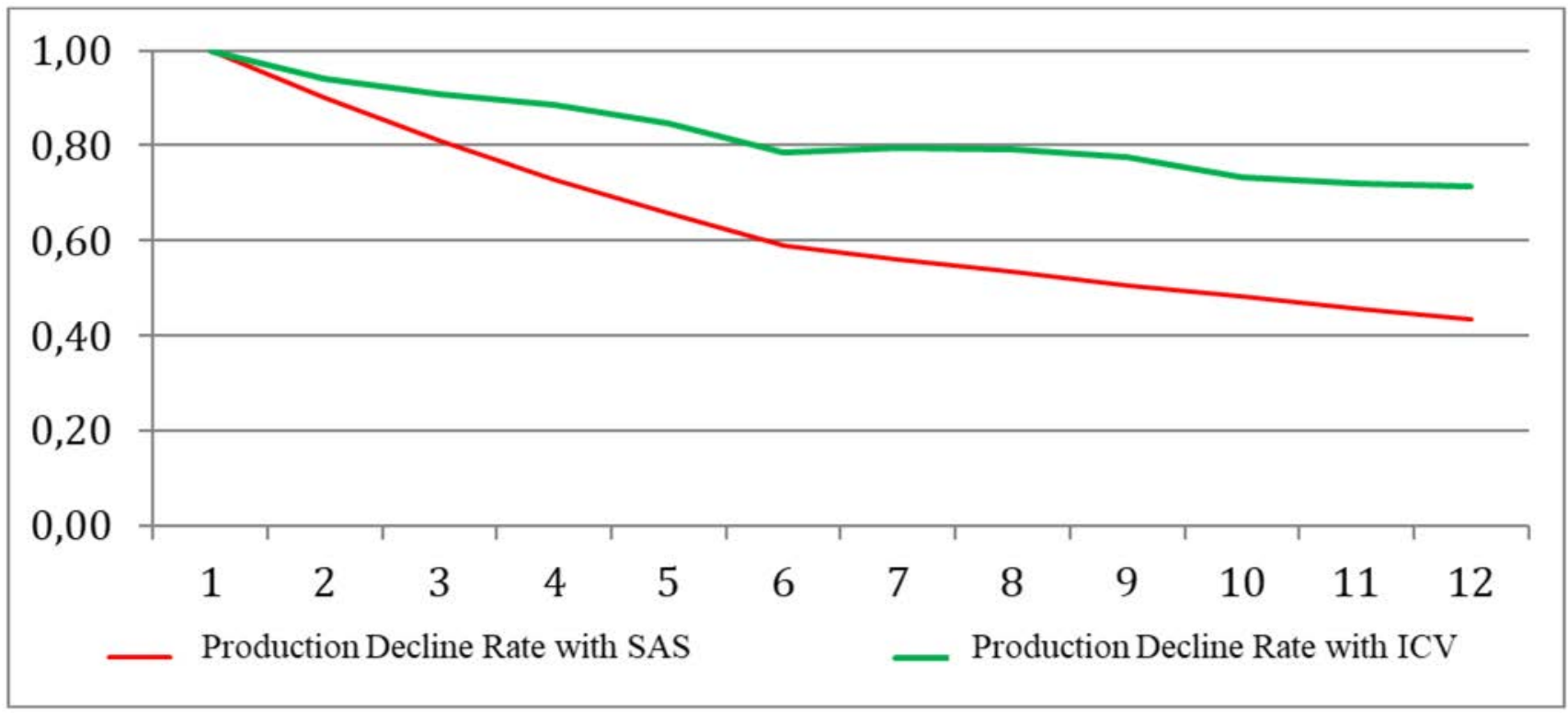

Figure 23-Comparison of operation parameters of well equipped with a smart well with hydraulic valves and standard completion wells

When using ICV valves with control lines in wells, restrictions on the number of zones are associated with the ability of open hole packers and wellhead equipment to pass a certain number of hydraulic and electrical control lines. Also, in the conditions of the field named after Yu. Korchagin, the limiting factor in the application of these systems (due to the presence of hydraulic and electrical lines) was the need to run the completion string with rotation for wells with a long horizontal section.

Another pilot project was the introduction of the all in one electric smart well. This system has a fully electronic control and works with several measuring stations, united by one control line through a telemetry system. Each station has 2 pressure and temperature sensors, a Venturi flowmeter, and a water cut sensor (Figure 24).

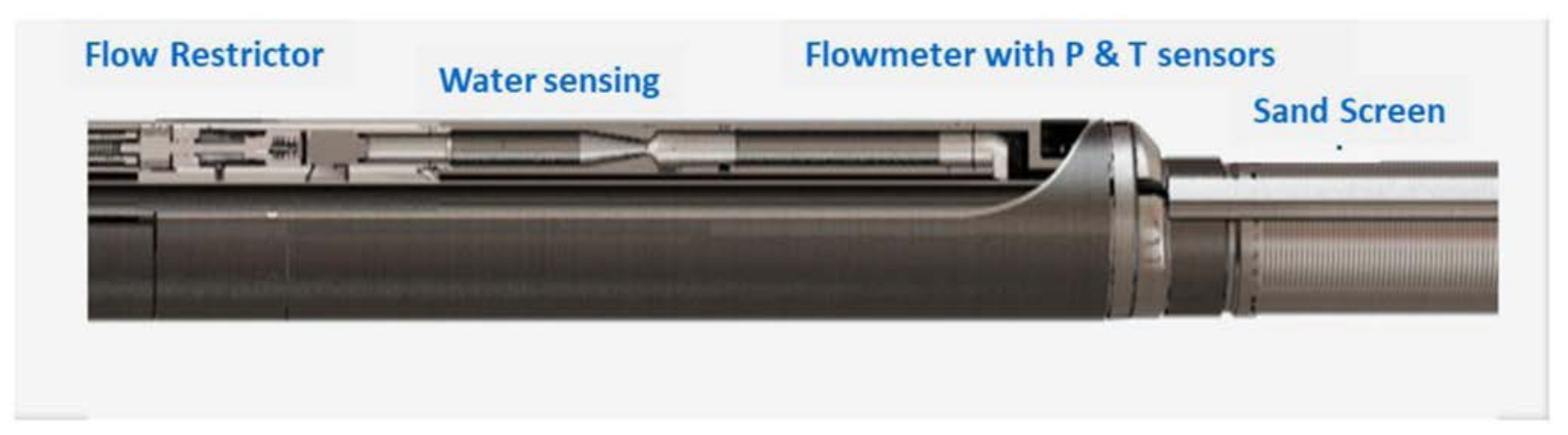

Figure 24-All in one electrical intelligient completion system design

Electric drive inflow control provides stepless position control. The installation of sensors above the inflow regulator allows carrying out hydrodynamic studies while simultaneously producing from other intervals. This will allow to collect a large amount of data on the behavior of the reservoir with minimal impact on the production process itself. Ground modules and modules for operational data collection have a special design that takes into account the need to monitor the system operation and to optimize client interfaces. 
Currently, 11 wells are equipped with smart wells at the Yu. Korchagin field. Including 4 dual wells with the ability to control the inflow along the wellbores and 7 horizontal wellbores (4 with hydraulic and 3 with electric control).

\section{Conclusion}

For the first time in Russia, the most advanced technologies for completion and continuously monitoring horizontal wells were introduced at the same field. A real example of the evolution of completion systems (from slotted filters to an electric smart well) is shown by the example of the operation of long horizontal wells in the oil rim development. Comparison of various completion systems based on real works on the same field is given. Recommendations on the use of technology for offshore wells in the development of an oil rim are presented. In addition, the results of all pilot projects were a great contribution at the stage of drafting the project for the development of other fields in the North Caspian.

\section{References}

1. Svarovskaya M., Senkov A., Zolotukhin, A., "Russian Offshore: Gained Experience and Development Perspectives of the Northern Block of the Caspian Sea", SPE 171316, SPE Russian Oil \& Gas Exploration and Production Technical Conference and Exhibition, Moscow, Russia, 14-16 October 2014.

2. Semikin D., Senkov A., Surmaev A., Prusakov A., Leung E.: SPE 176563 “Autonomous ICD Well Performance Completed With Intelligent Inflow Tracer Technology in the Yuri Korchagin Field in Russia" October 2015

3. Chertenkov M, Deliya S.V., Semikin D.A., Brown G.A., Bayanova A., Kanevsky E., Nukhaev M., Shapovalov A., Pormeyster Y.: SPE 159581 "Gas Breakthrough Detection and Production Monitoring From ICD Screen Completion on Lukoil's Korchagina Field Using Permanently Installed Distributed Temperature Sensors” September 2012

4. Semikin D., Nukhaev M.: "Review of Production Monitoring System for Long Horizontal Wells and Contact Reserves" // EAGE 8G05, EAGE Horizontal Wells Conference, May 2017

5. Shtun S., Senkov A., Surmaev A.: SPE 181994 "Inflow Monitoring and Analysis Using Proprietary Intelligent Chemical Tracers in the Yuri Korchagina Field" October 2016

6. Shtun, S., Senkov, A. A., Abramenko, O. I., Matsashik, V. V., Mukhametshin I. R., Prusakov, A. V., Nukhaev M. T. "The Comparison of Inflow Profiling Technologies for ERD Wells Including PLT, Fiber Optics DTS, Stationary Chemical Tracers: A Case Study from the Caspian offshore Yuri Korchagin Field in Russia"// 188985-MS SPE Conference Paper - 2017 